\title{
Percutaneous Mitral Valvotomy in Patients Eighteen Years Old and Younger. Immediate and Late Results
}

\author{
Cláudia Mattos, Sérgio Luiz Navarro Braga, César Augusto Esteves, José Matos Brito Castello Branco, \\ Nisia Lira Gomes, Mercedes Maldonado, Valmir Fernandes Fontes
}

São Paulo, SP - Brazil

\begin{abstract}
Objective - To analyze immediate and late results of percutaneous mitral valvotomy (PMV) in patients $\leq 18$ year.

Methods - Between August' 87 and July '97, 48 procedures were performed on 40 patients. The mean age was 15.6 years; $68.7 \%$ were females four of whom were pregnant.
\end{abstract}

Results - Success was obtained in $91.7 \%$ of the procedures. Immediate complications were severe mitral regurgitation (6.3\%) and cardiac tamponade (2.0\%). Late follow-up was obtained in $88.8 \%$ of the patients (mean value $=43.2 \pm 33.9$ months). NYHA functional class (FC) I or II was observed in $96.2 \%$ of the patients and restenosis developed in five patients, at a mean follow-up of $29.7 \pm 11.9$ months. Three patients presented with severe mitral insufficiency and underwent surgery. Two patients died.

Conclusion - PMV represents a valid therapeutic option in young patients. In these patients, maybe because of subclinical rheumatic activity, restenosis may have a higher incidence and occur at an earlier stage than in others persons.

Keywords: mitral valvotomy, restenosis, teenagers.
Rheumatic valvar disease is still relatively frequent in developing countries, occurring in $25 \%$ to $40 \%$ of patients with cardiac diseases ${ }^{1}$. Surgical treatment through closed mitral commissurotomy, was initially proposed by Cutler et $\mathrm{al}^{2}$ in 1923. As an alternative to surgical treatment, Inoue et $\mathrm{al}^{3}$ in 1984, described a technique for percutaneous mitral valvotomy using a balloon catheter created by themselves and an anterograde access. Using this via, a valvar opening is created by the separation of the commissures by the centrifugal force generated by the balloon at the level of the mitral valvar ring. Immediate and late results obtained with percutaneous treatment throughout the years have been found to be similar to those obtained with classical surgical treatment, with the advantage of having a lower rate of morbidity and mortality ${ }^{4-6}$. Therefore, percutaneous mitral valvotomy is now the first therapeutical choice for treating mitral stenosis in selected patients.

Patients with rheumatic mitral stenosis who undergo surgery during childhood or adolescence, need to undergo other procedures during the follow-up of their disease due to the incidence of rheumatic attacks at this early age ${ }^{7}$. These new interventions may increase morbidity and mortality in this young group. Taking these data into consideration, we decided to use PMV as a first-choice therapy at our institution in patients $\leq 18$ years.

The objective of this study was to describe early results and late clinical follow-up of patients at this young age who underwent PMV for treatment of rheumatic mitral stenosis.

\section{Methods}

Between August ' 87 and July '97, 882 percutaneous procedures for mitral valve openings were performed at our institution in patients previously selected. Forty-eight (5.4\%) were performed in 40 patients $\leq 18$ years. In this group, mean age ranged from 10 to 18 years, with a mean age of 15.6 , and 33 $(68.7 \%)$ were females. All patients were in sinus rhythm, and only one patient had had a previous surgical mitral valve commissurotomy. It is important to note that four patients 
$(8.3 \%)$ were pregnant and did not respond to conventional clinical therapy, necessitating the intervention between the $13^{\text {th }}$ and $34^{\text {th }}$ weeks of pregnancy. Before percutaneous mitral valvotomy, six patients (15\%) were in NYHA functional class (FC) IV, 21 (52.5\%) in FC III and 13(32.5\%) in FC II (table I).

The indications for the procedure were a mixture of clinical, radiological and echocardiographic findings, that is, symptomatic patients with a mitral valve area $\leq 1 \mathrm{~cm}^{2}$ and a score $\leq 12$ points by echocardiographic criteria ${ }^{8}$. The presence of thrombus in the left atrium (LA) Ano/OR, associated mitral regurgitation $>2+/ 4+$, according to Seller's classification ${ }^{9}$ were considered exclusion criteria.

A Doppler echocardiogram was performed in all patients before the procedure, 48 hours afterwards and once a year during late follow-up. Valve anatomy, peak and mean diastolic gradients, and mitral valve area (MVA) calculated by planimetry were assessed in all patients. Morphology of the mitral valve and subvalvular apparatus was analyzed according to the criteria proposed by Wilkins et al $^{8}$, and mitral regurgitation was quantitated when present.

All selected patients underwent a Cardiac Catheterization both before and after the procedure. This study included right and left heart catheterization performed through the puncture of the right femoral vein and left femoral artery. Manometry was obtained, including right chamber pressures and the gradient between mean LA pressure and left ventricular end diastolic pressure. Left ventriculography was performed at $30^{\circ}$ in the oblique anterior view to analyze the mitral subvalvular apparatus and to quantitate mitral regurgitation, when present. Aortography at $45^{\circ}$ in the left anterior oblique view was obtained to assess associated aortic lesions. After valvotomy and consequent opening of the mitral valve, left atriography at $30^{\circ}$ in the left anterior oblique view was obtained to analyze LA emptying and another left ventriculography was performed to detect mitral regurgitation at this view.

Valvotomy was always performed using the anterograde access through the puncture of the atrial septum, as described by Brockenbrough ${ }^{10}$. Heparin (100U.i/kg) was given to all patients after puncture of the atrial septum. Both the double balloon and the Inoue techniques were used (table II).

The procedure was considered successful when the mitral valve area became $\geq 1.5 \mathrm{~cm}^{2}$ and when no complications, such as severe mitral regurgitation or left-to-right shunt $>1.5: 1$ through the residual atrial septal defect (ASD), occurred.

\begin{tabular}{|ll|}
\hline \multicolumn{1}{|c|}{ Table I - Methods (48 procedures) } \\
\hline Age (years) & $10-18($ mean $=15.5 \pm 2.2)$ \\
Sex Female & $33(68.7 \%)$ \\
Male & $15(31.3 \%)$ \\
Sinus rhythm & 48 \\
Previous commissurotomy & $1(2.0 \%)$ \\
Pregnancy & $4(8.3 \%)$ \\
Echocardiographic score & \\
Functional Class (NYHA) & $5-10($ mean $=7.7 \pm 1.3)$ \\
II & \\
III & $13(32.5 \%)$ \\
IV & $21(52.5 \%)$ \\
\hline
\end{tabular}

Restenosis was defined as a loss of $>50 \%$ of the mitral valve area obtained right after the procedure.

\section{Results}

Immediate Results - A transseptal puncture was performed without complications in 47 of the 48 procedures, and the mitral valve was successfully dilated in $44(91.7 \%)$ patients. In only one patient could the procedure not be completed due to a complication of the transseptal puncture with subsequent hemopericardium and signs of cardiac tamponade.

The mean mitral valve area assessed by planimetry and by the pressure half-time method increased from $0.86 \pm 0.21$ to $2.03 \pm 0.50 \mathrm{~cm}^{2}$ afterpercutaneous mitral valvotomy $(\mathrm{p}<0.00001)$. Doppler echocardiography showed a decrease in peak and mean gradients of $26.0 \pm 7.1$ to $13.7 \pm 3.9 \mathrm{mmHg}$ and from $15.3 \pm 5.4$ to $6.0 \pm 2.5$ ( $\mathrm{p}<0.00001)$ respectively, right after the procedure.

Manometry data obtained at right and left catheterization showed a decrease in mean LA pressure: $29.0 \pm 7.3$ to $12.5 \pm-$ $6.1 \mathrm{mmHg}(\mathrm{p}<0.00001)$. The samehappened to the mean diastolic gradient and the mean pulmonary pressure, which decreased respectively from $21.7 \pm 6.08$ to $4.4 \pm 3.0 \mathrm{mmHg}(\mathrm{p}<0.00001)$ and from $42.1 \pm 15.6$ to $28.7 \pm 11.5 \mathrm{mmHg}(\mathrm{p}<0.005)$ (tableIII).

Regarding mitral regurgitation, which represents the most frequent complication of this procedure, of 37 patients with no previous mitral regurgitation, 28 did not have it at the control ventriculography. Five patients developed a 1+/4+ mitral regurgitation, according to Seller's classification, one a $2+/ 4+$, two a $3+/ 4+$ and one $4+/ 4+$. Of nine procedures with previous $1+/ 4+$ mitral regurgitation, six did not show any change while three increased their regurgitation to a $2+/ 4+$. In the only procedure with an initial $2+/ 4+$ mitral regurgitation, no change occurred in the degree of regurgitation at a control ventriculo-

\begin{tabular}{|cc|}
\hline \multicolumn{2}{|c|}{ Table II - Techniques used } \\
\hline 1) Double balloon * & -36 procedures $(76.6 \%)$ \\
\hline$\cdot$ & $20+20=20$ \\
$20+18=8$ \\
$18+15=4$ \\
• & $18+18=3$ \\
& $20+15=1$ \\
\hline EBDA/BSA $\left(\mathrm{cm}^{2} / \mathrm{m}^{2}\right)=3.6 \pm 0.29$ (effective balloon dilation area/body \\
surface)
\end{tabular}

\begin{tabular}{|c|c|c|c|}
\hline \multicolumn{4}{|c|}{ Table III } \\
\hline Echocardiogram & Pre & Post & $\mathrm{P}$ \\
\hline $\operatorname{MVA}\left(\mathrm{cm}^{2}\right)$ & $0.86 \pm 0.21$ & $2.03 \pm 0.50$ & $<0.00001$ \\
\hline Peak Gradient (mmHg) & $26.0 \pm 7.1$ & $13.7 \pm 3.9$ & $<0.00001$ \\
\hline Mean Gradient (mmHg) & $15.3 \pm 5.4$ & $6.0 \pm 2.5$ & $<0.00001$ \\
\hline \multicolumn{4}{|l|}{ Catheterization } \\
\hline $\mathrm{LA}(\mathrm{mmHg})$ & $29.0 \pm 7.3$ & $12.5 \pm 6.1$ & $<0.00001$ \\
\hline Mean Gradient (mmHg) & $21.7 \pm 6.8$ & $4.4 \pm 3.0$ & $<0.00001$ \\
\hline Mean PA pressure (mmHg) & $42.1 \pm 15.6$ & $28.7 \pm 11.5$ & $<0.005$ \\
\hline
\end{tabular}


graphy (fig. 1). Therefore, mitral regurgitation was found to develop to appear or increase in intensity in $12(25.4 \%)$ of the 47 completed procedures, being $3+/ 4+$ and $4+/ 4+$ in $3(6.3 \%)$.

The development and the measurement of the ASD were assessed by oximetry (QP/QS<1.5/1) and by Doppler echocardiogram. In 10 procedures where a left-to-right shunt was detected, the ASD was not greater than $3 \mathrm{~mm}$ in diameter.

There were no embolic events or hospital deaths in this group of patients.

Success was not obtained in four procedures in one perforation of the LA free wall occurred during the atrial septal puncture with consequent cardiac tamponade that required emergent surgery. In the remaining three, after balloon valvotomy, severe mitral regurgitation was detected by left ventriculography, and all three patients underwent urgent mitral valve replacement surgery

Late results - Late follow-up was obtained in 32 (80\%) of the 40 patients who underwent percutaneous mitral valvotomy. Twenty-four $(75 \%)$ were females and mean followup was $43.2 \pm 33.9$ months.

Of these 32 patients (fig. 2), three were referred for elective valve replacement surgery (two because of mitral insufficiency and one because of restenosis). In the remaining 29 patients,

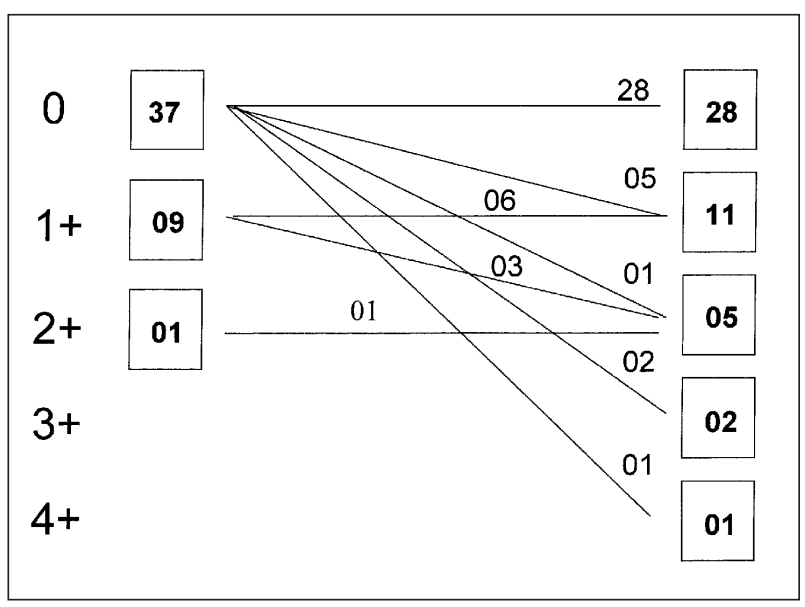

Fig. 1 -Mitral insufficiency (47 procedures).

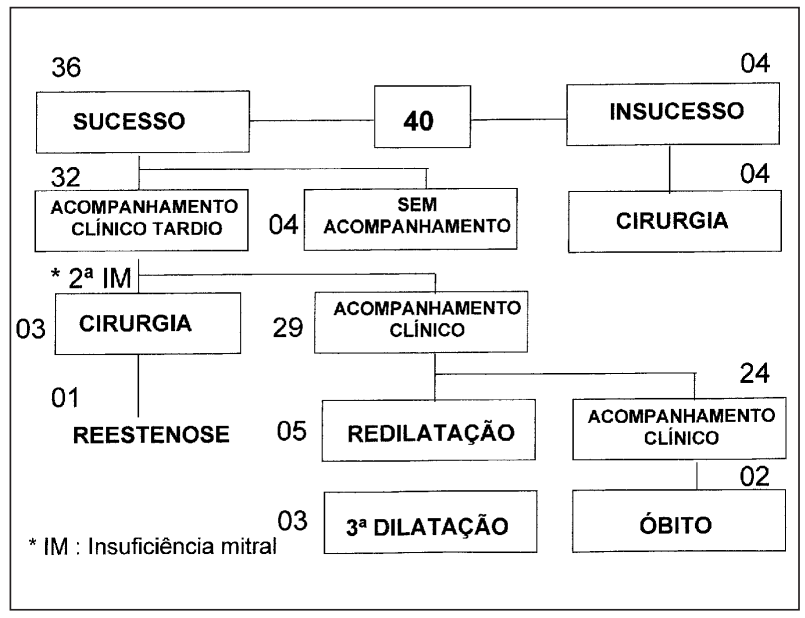

Fig. 2 - Population (40 patients) five developed restenosis in a mean period of $29.7 \pm 11.9$ months and were successfully redilated. In three of these a third redilation was performed due to a new restenosis. Therefore, eight redilations were performed in five patients.

In this group of 40 patients, two late deaths occurred, one probably due to restenosis (acute pulmonary edema) and the other due to a non related cause (septicemia).

A better NYHA FC at follow-up was observed with significant improvement in the quality of life of these patients. In the observed follow-up period, $24(75 \%)$ patients were in NYHA FC I and only three $(11.2 \%)$ were in FC II or III. At follow-up, 30 patients remained in sinus rhythm, and only two developed atrial fibrillation. All four pregnant women had a term cesarean delivery while in FC I and no fetal deaths or associated malformations occurred.

Echocardiographic parameters of MVA and peak and mean gradients at follow-up are described in table IV.

\section{Discussion}

Data reporting the immediate results obtained in this group of patients do not differ significantly from those observed in the general population undergoing this type of procedure ${ }^{11}$. The efficacy of this method in this age group was demonstrated by the final MVA, the reduction of mean LA pressure, of the pulmonary artery pressure and of the mean diastolic transmitral gradient.

As for immediate complications, a residual ASD was observed in $21.2 \%$ of the patients by a Doppler echocardiogram performed 48 hours after the procedure, a phenomenon also reported in the majority of published studies ${ }^{10}$. In our experience, the created defect was always small, and a significant residual shunt was not observed in any of the cases. We think that the persistence of this defect occurs mainly in those patients where final results of the MVA are considered suboptimal $\left(<1.5 \mathrm{~cm}^{2}\right)$, due to the persistence of an elevated pressure in the left atrium ${ }^{12}$.

The incidence of mitral regurgitation $(27.2 \%)$ is similar to that observed by us in the general population $(29.2 \%)^{11}$. As is well known, the main predictors of this complication are oversizing of the balloon ${ }^{13}$, commissural or leaflet calcification or both and the intensity of the involvement of the mitral subvalvar apparatus ${ }^{14}$. In our series of patients, the development of severe mitral regurgitation was directly related to the degree of valvar involvement before valvotomy, especially when MVA was $\leq 0.9 \mathrm{~cm}^{2}$.

In this group, because patients were young, calcification was uncommon, and the involvement of the subvalvar apparatus was usually mild, our main concern was the exact diameter of the balloon, especially when MVA was $<0.9 \mathrm{~cm}^{2}$.

\begin{tabular}{|lccl|}
\hline \multicolumn{4}{|c|}{ Table IV } \\
\hline Echocardiogram & Post & Late & P \\
\hline Mitral valve area $\left(\mathrm{cm}^{2}\right)$ & $2.03 \pm 0.50$ & $1.91 \pm 0.50$ & NS * \\
Peak gradient $(\mathrm{mmHg})$ & $\begin{array}{c}13.7 \pm 3.9 \\
\text { Mean gradient }(\mathrm{mmHg})\end{array}$ & $\begin{array}{c}11.5 \pm 4.9 \\
\text { NS }\end{array}$ & NS \\
*NS- nonsignificant.e & & & \\
\hline
\end{tabular}


Therefore, when the double balloon technique was employed, we used an EBDA/BSA $<3.5$ relation and, when the Inoue balloon was the one chosen, we used the formula suggested by the author and subtracted $1 \mathrm{~mm}$. Even having done that, three procedures were followed by a $3+/ 4+$ or $4+/ 4+$ mitral regurgitation, which required urgent surgery. Some degree of involution of acute mitral insufficiency has been described in the literature in a certain percentage of patients ${ }^{15}$ and is probably related to the elastic retraction of the mitral ring, to commissural fusion and fibrosis and to the improvement of posttraumatic dysfunction (edema) of the papillary muscles caused by the balloon. However, this phenomenon was not observed in this group of patients.

Late follow-up data obtained at a mean period of $43.2 \pm 33.9$ months showed that the great majority of the patients $(88 \%)$ were in NYHAFC I and atrial fibrillation occurred in only two patients.

No statistically significant difference occurred between immediate and late echocardiographic parameters, such as MVA, mean LA pressure, mean pulmonary artery pressure and, finally, mean transmitral diastolic gradient, which demonstrates the efficacy of the procedure in the medium-term follow-up.

We believe that the relatively high index of restenosis (15.6\%) detected in five of the 32 patients in a relatively short period of time ( $29.7 \pm 11.9$ months) is above the observed the index described in the literature for the general population, which is around $10 \%$ in five years, both for percutaneous or surgical treatment ${ }^{15-17}$. The observed re-stenosis in the present study is probably not directly related to the use of undersized balloons in both techniques, because our immediate results do not differ significantly from those previouly observed by us.

Predisposing factors related to development of restenosis classically described are: old age, atrial fibrillation and a high echocardiographic score index (mainly the degree of thi- ckening and the presence of calcium in the leaflets) ${ }^{18}$. In this group, these findings were uncommon because of the young age of the patients, and we think that restenosis may have been caused by recurrent subclinical rheumatic attacks, which usually can not be detected clinically or by laboratory tests.

Based on these results and considering the problem imposed by future re-interventions, we believe that percutaneous treatment should be the primary intervention, because its immediate and late results are similar to those obtained by surgery ${ }^{4-6}$, which has a higher morbidity. Another advantage of the percutaneous procedure is that redilations can be performed without technical difficulties in the additional procedures and without a higher incidence of complications.

It is well known that rheumatic disease has a chronic and progressive course and young patients are prone to undergoing more then one valvular procedure during their lifetime. Therefore, when this becomes necessary, surgery can be performed without the inherent risks of a previous thoracotomy.

Analyzing these data, we believe that percutaneous mitral valvotomy is a valid therapeutic option for the treatment of severe rheumatic mitral stenosis in patients under 18. In this population, the incidence of restenosis is relatively higher and occurs earlier than in the general population. This is probably related to the occurrence of subclinical attacks of rheumatic disease or to a more malign valvar involvement of the disease in this age group.

It has also been demonstrated that the technique can be repeated in cases of restenosis without additional technical implications or more complications. We therefore conclude that percutaneous mitral valvotomy should be the method of choice for the treatment of severe rheumatic mitral stenosis in patients under 18 years of age.

\section{References}

1. Community control of rheumatic heart disease in developing countries. A major public health problem. Who Chron 1980; 34: 336.

2. Cutler EC, Levine As, Biy CS. Surgical, treatment of mitral stenosis: Experimental and clinic studies. Arch Surg 1924; 689-821.

3. Inoue K, Owaki T, Nakamura T, Kitamura F, Miyamoto N. Clinical application of transvenous mitral commissurotomy by a new balloon catheter. J Thorac Cardiovasc Surg 1984; 87: 395-402.

4. Can the long-term outcomes of percutaneous balloon mitral valvotomy and surgical commissurotomy be expected to be similar? J Heart Valve Dis 1995; 4: 446-52.

5. Arora R, Nair M, Kalra G, et al. Immediate and long-term results of balloon and surgical closed mitral valvotomy. A randomized comparative study. Am Heart J 1993; 125: 1091-3.

6. Feldman T. Hemodynamic results, clinical outcomes and complications of Inoue balloon mitral valvotomy. Cathet Cardiovasc Diagn 1994; 2: 2-7.

7. Kirklin JW, Barrat-Boyes BG. Cardiac Surgery, $2^{\text {nd }}$ edition, 1993; 440-51.

8. Wilkins GT, Weyman AE, Abaseal VM, Block PC, Palacios IF. Percutaneous balloon dilatation of the mitral valve: an analysis of echocardiography variables related to outcome and the mechanism of dilatation. Br Heart J 1988; 60: 299-308.

9. Seller RD, Levy MJ, Amplatz K, Lillehei CW. Retrograde cardioangiography in acquired cardiac disease: technique, indications and interpretation of 100 cases. Am J Cardiol 1964; 14: 437
10. Mullins CE. Transeptal left heart catheterization: Experience with a new technique in 520 pediatric and adult patients. Pediatr Cardiol 1983; 4: 239-46.

11. Braga SLN, Esteves CA, MenegheloZ, Sousa JEMR. Valvoplastias mitral e aórtica por cateter balão. Socesp Cardiologia. Atualização e Reciclagem 1994; 466-75.

12. Palacios IF, Block PC, Wilkins GT, Weyman AE. Follow-up patients undergoing percutaneous mitral balloon valvotomy. Analysis of factors determining restenosis. Circulation 1989; 79: 573-9.

13. Roth RB, Block PC, Palacios IF. Predictors increased mitral regurgitation after percutaneous mitral balloon valvotomy. Cath and Card Diag 1990; 20: 17-21.

14. Hung JS, Cherm MS, WuJJ, et al. Short and long-term results of catheter balloon percutaneous transvenous mitral commissurotomy. Am J Cardiol 1991; 67: 854-62.

15. Palacios IF, Block PC, Wilkins GT, Weyman AE. Follow-up of patients undergoing perutaneous mitral balloon valvotomy. Analysis factors determining restenosis. Circulation 1989; 79: 570-3.

16. Vahaniar A, Michiel PL, Cmier B, et al. Results of percutaneous mitral commissurotomy in 200 patients.Am J Cardiol 1989; 63: 847-52.

17. Desidiri A, Vanduperrer O, Serra A, et al. Long-term (9 to 33 months) echocardiografic follow-up after successful percutaneous mitral commissurotomy. Am J Cardiol 1992; 69: 1602-6.

18. Pan M, Medina A, Lezo JS, et al. Factors determining late sucess after mitral balloon valvulotomy. Am J Cardiol 1993; 71: 1181-5. 